\title{
The view of technological innovation in coal industry under the vision of carbon neutralization
}

\author{
Quansheng $\mathbf{L i}^{1,2}$ (D)
}

Received: 13 April 2021 / Revised: 28 May 2021 / Accepted: 8 July 2021 / Published online: 4 September 2021

(C) The Author(s) 2021

\begin{abstract}
This paper analyzed the current situation and development trends of energy consumption and carbon emissions, and the current situation and development trend of coal consumption in China. In the context of recently established carbon peak and carbon neutralization targets, this paper put forward the main problems associated with the green and low-carbon development and utilization of coal. Five key technological innovation directions in mining were proposed, including green coal development, intelligent and efficient mining, low-carbon utilization and conversion of coal, energy conservation and emission reduction, carbon capture, utilization and storage (CCUS). Focusing on the above technological innovation directions, it is suggested to carry out three basic theories, including the theory of green efficient intelligent mining, clean and low-carbon utilization and transformation of coal, and CCUS. Meanwhile, it is proposed to develop 12 key technologies, including green coal mining and ecological environment protection, efficient coal mining and intelligent mine construction, key technologies and equipment for efficient coal processing, underground coal gasification and mining, ultra-high parameter and ultra-supercritical power generation technology, intelligent and flexible coal-fired power generation technology, new power cycle coal-fired power generation technology, the development of coal-based special fuels, coal-based bulk and specialty chemicals, energy conservation and consumption reduction, large-scale and low-cost carbon capture, $\mathrm{CO}_{2}$ utilization and storage. Finally, necessary measures from the governmental perspective were also proposed.
\end{abstract}

Keywords Carbon neutralization - Technological innovation - Clean utilization of coal · Clean transformation of coal · CCUS

\section{Introduction}

The discovery and utilization of fossil energy has brought human beings from farming to industrial civilization. Although industrialization has enabled tremendous progress in human society for more than two hundred years, it has also caused severe environmental damage and high amount of carbon emissions. The estimated total amount of

Quansheng Li

quansheng.li@chnenergy.com.cn

1 China Energy Investment Group Co., Ltd., Beijing 100011, China

2 State Key Laboratory of Water Resource Protection and Utilization in Coal Mining, Beijing 102209, China
$\mathrm{CO}_{2}$ produced by the combustion of fossil fuels has reached 2.2 trillion tons. The global average temperature has risen by $1.1^{\circ} \mathrm{C}$ since 1906 , and if the trend continues the commonly discussed $2{ }^{\circ} \mathrm{C}$ threshold will be exceeded in the middle of this century if still following this trend. Climate change has already become a global nontraditional security issue.

The Paris Agreement adopted at the Paris Climate Conference in late 2015 established a new mechanism for international climate governance after 2020, and proposed the goal of controlling global temperature rise not to exceed $2{ }^{\circ} \mathrm{C}$ and striving to control it below $1.5^{\circ} \mathrm{C}$, to protect the ecological security of the earth. However, the global response to climate change is still facing an urgent situation, and the targets of the Intended Nationally 
Determined Contributions (INDC) set by each country are far from the reality (United Nations 2020; Intergovernmental Panel on Climate Change (IPCC) 2018a, b).

For a long time, China has actively participated in and led global climate governance, incorporating the tasks of reducing greenhouse gas emissions into the National FiveYear Plan and medium and long-term development strategic goals. In terms of emission reduction policies, China's energy conservation and emission reduction actions have yielded remarkable results through a series of measures such as adjusting industrial structure, optimizing energy structure, improving energy efficiency, establishing a carbon trade market, and increasing carbon sink ( $\mathrm{Yu}$ et al. 2021). In 2019, China's $\mathrm{CO}_{2}$ emissions per unit of GDP (carbon intensity) decreased by $48.1 \%$ compared with 2005 , and non-fossil energy accounted for $15.3 \%$ of total energy production. China has already achieved in advance the 2020 climate action target ahead of schedule (The Ministry of Ecology and Environment 2020; Li et al. 2021a).

Especially since the 18th National Congress of the Communist Party of China, President Jinping Xi has attached great importance to the realization of an ecological civilization and environmental protection. The overall layout of "five in one" has been steadily advanced, and the five development concepts of "innovation, coordination, green, openness and sharing" have been deeply rooted in the hearts of the people. On September 22, 2020, President Jinping Xi made a solemn promise at the 75th United Nations General Assembly: China's carbon dioxide emissions will peak by 2030 and strive to achieve carbon neutrality by 2060 . Subsequently, at the United Nations Climate Ambition Summit on December 12, 2020, President Jinping Xi further put forward clear indicators and requirements for China's response to climate change, in which China will be guided by new development concepts, to promote a comprehensive green transformation of economic and social development while fostering high-quality development, and down-to-earthly to fulfill the peak of carbon dioxide emissions by 2030 , and strive to achieve the goal of carbon neutrality by 2060 , which make greater contributions to the global response to climate change ( $\mathrm{Zhu}$ et al. 2020).

The 2020 Central Economic Work Conference emphasized the need to successfully achieve carbon peak and carbon neutrality targets, formulate an action plan for carbon emissions peaking by 2030 , accelerate the adjustment and optimization of the industrial structure and energy structure, promote peak coal consumption as soon as possible while vigorously developing new energy sources, and improve the dual control system of energy consumption. The proposal of this series of goals is of great strategic significance, which demonstrates China's commitment to tackling climate change, and indicating the direction for its low-carbon energy transition.

\section{China's energy consumption structure and carbon emissions}

\subsection{China's energy production and consumption structure}

In 2019, China's total national energy consumption was 4.86 billion tons of standard coal, a year-on-year increase of 3.3\%. As shown in Fig. 1, among them, fossil energy accounted for $84.7 \%$, coal, oil and gas consumption accounted for $57.7 \%, 18.9 \%, 8.1 \%$, and non-fossil energy accounted for $15.3 \%$ (China Energy Statistical Yearbook 2019 2020).

In the same year, global energy consumption was approximately 14.45 billion tons of oil equivalent, a yearon-year increase of $1.3 \%$.Among them, fossil energy accounted for $84.3 \%$, coal oil and gas consumption accounted for $27.0 \%, 33.1 \%, 24.2 \%$, and non-fossil energy consumption accounted for $15.7 \%$ (BP Amoco 2020). Thus, compared with the global average, coal accounted for a relatively high proportion of China's energy production in 2019 (Fig. 1).

\subsection{China's energy-related carbon emissions status}

Carbon dioxide emissions from the burning of fossil fuels are the promary contributor to greenhouse gas emissions. According to the IPCC 5th Assessment Report, carbon dioxide emissions accounted for about $76 \%$, methane emissions accounted for about $16 \%$, nitrous oxide accounted for about $6 \%$, and fluorinated gases accounted for about $2 \%$, of global greenhouse gas emissions, as shown in Fig. 2. The sources of carbon dioxide emissions included fossil energy combustion, industrial processes, forest and land use changes, agriculture, etc. The carbon dioxide emissions caused by fossil energy combustion was absolutely dominant, accounting for about $85 \%$ (Intergovernmental Panel on Climate Change (IPCC) 2018a, b) (Figs. 2, 3).

In 2019, China's carbon emissions from fossil energy consumption were 9.8 billion tons, accounting for $28.8 \%$ of global carbon emissions, as shown in Fig. 4. This corresponds to an increase of $3.4 \%$ year-on-year compared to 2018, and 6 times the global average growth rate of emissions (BP 2019).China's carbon dioxide emission intensity per unit of GDP was 8.4 tons/10,000 US dollars, which were 8.3 times, 7.4 times, 5.1 times, and 3.2 times those of France (BP 2019), the United Kingdom, Japan, and the United States, respectively. Because China's 
energy consumption structure was dominated by coal, carbon emissions generated by coal consumption accounted for $75.7 \%$ ( $\mathrm{Li}$ et al. 2021b) of the carbon emissions from fossil fuel combustion, as shown in Fig. 5. Thus, China's coal-dominant resulted in higher carbon emission intensity for the entire energy system. Consequently, energy structure optimization should play a vital role in China's long-term carbon reduction strategy (Figs. 4, 5).

\subsection{China's coal consumption status and development trend}

In 2018, China's total coal consumption was 3.97 billion tons (Ge et al. 2015; Zhu et al. 2020), which was equivalent to about 2.83 billion tons of standard coal, of which industry consumed 2.71 billion tons of standard coal, accounting for $95.7 \%$. In the same year, China's total energy consumption was 4.76 billion tons of standard coal, of which 3.11 billion tons of standard coal was consumed by industrial energy, and $87 \%$ of energy consumption for industrial development came from coal.

As shown in Fig. 6, coal consumption by the power industry was the largest component, accounting for $48.7 \%$ of China's total coal consumption. Nearly half of the country's coal was used for power generation. Coal consumption in metal smelting and processing, petroleum and coal processing and conversion, coal mining and washing, chemical raw materials and products and other industries accounted for $12.9 \%, 12.2 \%, 6.1 \%, 5.9 \%$ and $14.2 \%$, respectively, of coal consumption. The power industry, petroleum and coal transformation industry, and chemical raw materials and products were the three major users of coal resource consumption in China, and these thus represent key industries for the clean and efficient use of coal (Fig. 6).

China's energy resource structure is rich in coal, poor in oil, and less in gas, and the cost of coal development and utilization is relatively low. China's proven coal reserves

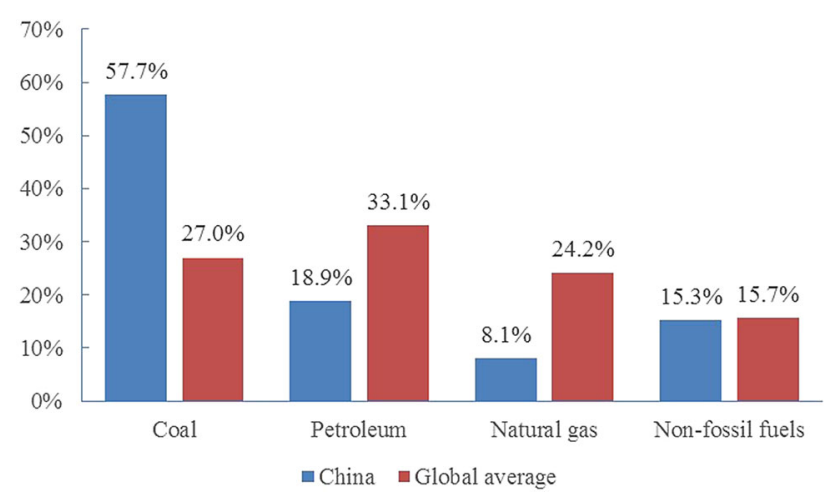

Fig. 1 Domestic and foreign energy consumption structure (BP Amoco.Statistical Review of World Energy 2020)

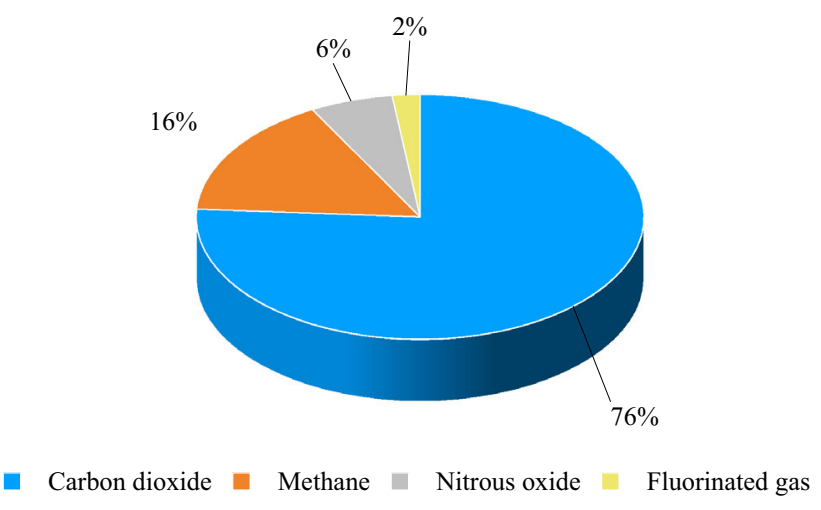

Fig. 2 Greenhouse gas emission structure

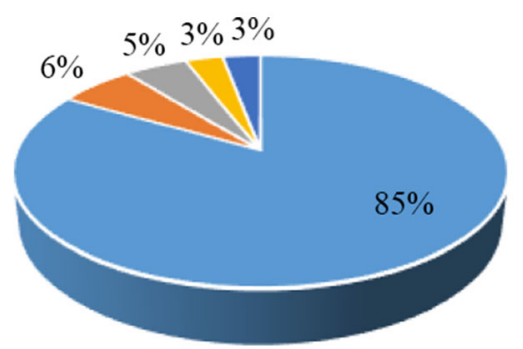

$\begin{array}{ll}\text { - Energy burning } & \text { - Industry process - Forest land } \\ \text {-Agriculture } & \text { - Others }\end{array}$

Fig. 3 Carbon dioxide emission source

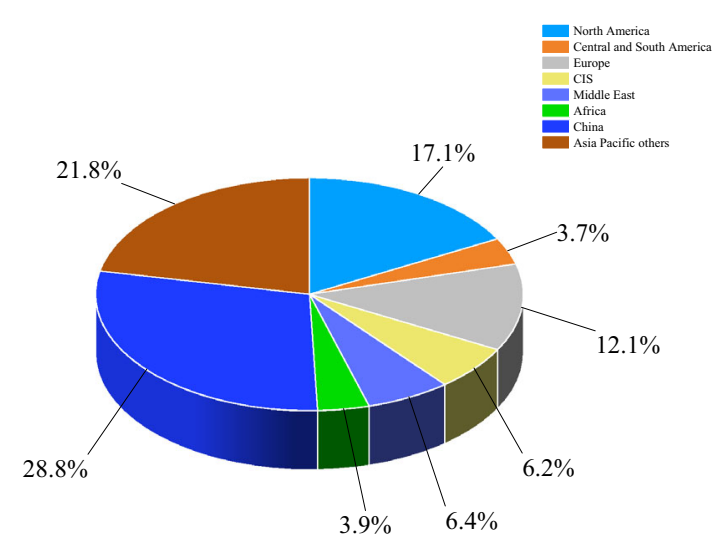

Fig. 4 Percentage of carbon emissions by major economies in 2019 (BP Amoco.Statistical Review of World Energy 2020)

are about 1.67 trillion tons, accounting for $96 \%$ of its fossil fuel reserves. According to the "Research on China's Coal Clean, Efficient and Sustainable Development and Utilization Strategy" by the Chinese Academy of Engineering, it is estimated that by 2030, coal will account for $50 \%$ of China's primary energy structure. Thus, in the medium to long term, coal is expected to remain China's main energy source. Under the goal of carbon neutrality, realizing the safe, efficient, green, and low-carbon 
development and utilization of coal through technological and management innovation is of great significance to guarantee hina's energy security and high-quality economic development.

\section{Key problems in the green and low-carbon development and utilization of coal}

At the 6th meeting of the Central Leading Group of Finance and Economics, June 3, 2014, President Jinping Xi pointed out that: the large-scale development and utilization of coal has brought two major problems. One is that coal development destroys groundwater and surface ecology, the other is air pollution and high carbon emissions caused by coal utilization. These problems are embodied in the following three aspects.

\subsection{Coal development severely damages water resources and the ecological environment}

China's water resources and coal resources are inversely distributed. The coal reserves and output of the five western provinces and regions account for more than $70 \%$ of the country's total amount, but water resources account for only $3.9 \%$ of the country's total. Furthermore, coal mining generates large quantities of mine water. At present, about 5 billion cubic meters of mine water is not effectively used wach year, which is equivalent to $50 \%$ of China's annual industrial and civil water shortage. Coal mining can also cause surface subsidence and vegetation degradation. The annual land damage area due to coal mining is about $7.0 \times 10^{4} \mathrm{hm}^{2}$, while the surface ecological restoration rate remains less than $30 \%$ (Yuan 2017). Therefore, the contradiction between coal development and ecological environment protection is acute, and the negative externality on the environment is prominent.

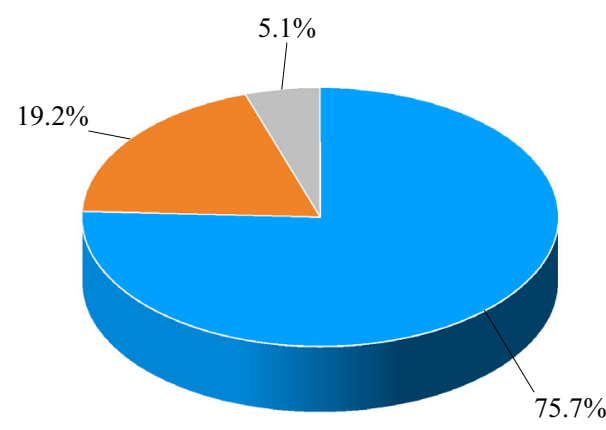

- Coal $\square$ Petroleum $\square \quad$ Natural gas

Fig. 5 China's energy consumption carbon dioxide emission structure

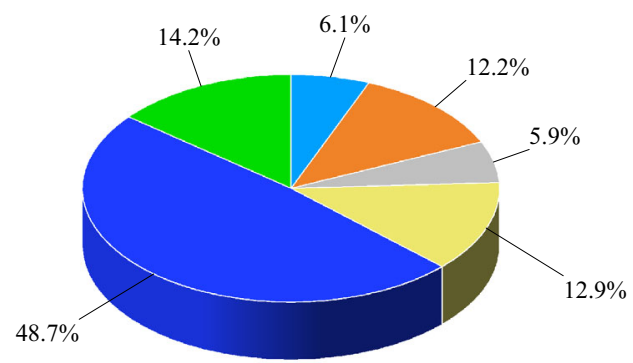

- Coal mining and washing
Metal smelting and processing

Fig. 6 Proportion of coal consumption in my country's major industries in 2018 (National Bureau of Statistics of China. China energy statistical yearbook 2019)

\subsection{Unreasonable approaches to coal development and high energy consumption of coal production}

Under the existing technical conditions, the amount of coal resources (referred to as "green coal resources") available for safe and efficient ecological development in China is relatively small, only $5.05 \times 10^{11}$ tons, accounting for about $10 \%$ of the national coal resources. Green coal resources can be mined for only 40-50 years (Zhang et al. 2021). With the exception of some mines in Shanxi, Inner Mongolia, Ningxia, Xinjiang and other provinces, where mining conditions are slightly better, the mining conditions in other coal fields are more complicated. At present, numerous problems have emerged during the development of large-scale coal production bases. The disorderly development of large-scale coal production bases has not only caused large-scale overcapacity, but also seriously jeopardized the economic benefits of the coal industry. At the same time, this has also caused China's high-quality resources to be occupied, consumed, and wasted too quickly.

Simultaneously, China's coal production also has problems with high amount of energy consumption. More attention should be devoted to output and safety, energy conservation, and scientific energy-saving indicator constraints to reduce the high energy consumption of coal production in China. The development of stand-alone technology should be pursued to continuously improve the installed capacity and operating efficiency of stand-alone machines, resulting in conservative design and selection standards and excessive wealth coefficient. Insufficient attention has been paid to the modern mining system and supporting equipment of coal mines, with little accounting for the energy consumption per ton of coal mined during the operation phase, and no clear requirements for energy efficiency, resulting in substantial energy waste. 


\subsection{Low energy efficiency and high emissions of coal utilization}

As a high-carbon energy source, coal will inevitably bring about carbon emissions during the process of utilization. China's $\mathrm{CO}_{2}$ emissions per unit of GDP are much higher than those of developed countries, and its total emissions now rank first in the world. The energy conversion efficiencies of key coal-consuming industries such as power, steel, and building materials still lag behind the international advanced levels.

In the power industry, the coal consumption for power supply was $374 \mathrm{gce} / \mathrm{kWh}$ in 2005 and has decreased to $312 \mathrm{gce} / \mathrm{kWh}$ by 2016 . The coal consumption for power supply by the most advanced generating sets reached $276 \mathrm{gce} / \mathrm{kWh}$, which is in line with global state-of-art levels, but the overall energy efficiency still has room for improvement. Subcritical coal-fired generating units in China's thermal power industry still account for about $70 \%$ of the total installed capacity, resulting in a low overall energy efficiency of coal-fired power generation in China. In advanced countries, coal-fired power generation is mainly supercritical and ultra-supercritical. There is still a huge gap between the overall energy efficiency level in China and the advanced level of $275 \mathrm{gce} / \mathrm{kWh}$ in developed countries.

Coal consumption by the iron and steel industry, a key energy-consuming sector in China, accounts for approximately $19 \%$ of total coal consumption. In 2016, the average comprehensive energy consumption per ton of steel dropped to $572 \mathrm{~kg}$ of standard coal for steel association member companies, which is close to the advanced level of comprehensive energy consumption in the international steel industry. However, owing to the high level of coal consumption, there is still considerable room for improved energy conservation and emission reduction.

\section{Scientific and technological innovation direction and main tasks for green and low-carbon coal development}

Taking the self-reliance of science and technology to support the green and low-carbon development and utilization of coal as the guiding ideology, based on the status quo of coal green development, low-carbon utilization and conversion technologies, focusing on the 5 major scientific and technological innovation directions, 3 basic theories that need to be investigated are proposed, and 12 key technologies should be developed to achieve near-zero emissions from coal development and utilization These aspects are summarized in Fig. 7.

\subsection{Scientific and technological innovation direction}

\section{(1) Green coal development}

From the perspective of carbon neutrality, ecological protection and resource recovery and reuse in the process of coal mining are the basis for green coal development and reduction of carbon emissions.

The carbon dioxide produced in mining areas can be partially absorbed by strengthening the scientific and technological innovation of groundwater resources and surface ecological protection, improving the level of surface ecological management in mining areas and increasing the carbon sink potential of mining areas.

Related research shows that carbon emissions from coal mining and washing and auxiliary processes account for about $40 \%$ of total emissions, while methane gas emissions account for $60 \%$. Therefore, the most effective way to reduce carbon emissions from coal mining is to improve the recycling and reuse of methane gas.

At the same time, it is necessary to strengthen scientific and technological research on the reuse of gangue and coal associated minerals, gas, mine water, geothermal energy, waste heat, etc., to reduce the use of coal by enterprises and outsourcing of electricity, and indirectly reduce the carbon emissions of enterprises in mining areas.

\section{(2) Intelligent and efficient coal mining}

The construction of intelligent, high-yield, and high-efficiency mines is the key for coal companies to improve their energy efficiency and reduce carbon emissions. Carbon emissions can be mitigated by decreasing energy consumption from the source by accelerating the technological innovation of full-face intelligent rapid excavation and intelligent coal mining and washing technologies, and improving the efficiency of coal mining and washing processes.

It would be also beneficial to explore technological innovations related to in-situ coal mining, such as underground coal gasification, which is the one of the disruptive technologies. If these technologies can achieve major breakthroughs, they will fundamentally alter the manner of coal production, which can significantly reduce energy consumption and carbon emissions.

(3) Clean and low-carbon utilization and conversion of coal

The development of advanced technology and equipment is an important measure to achieve clean and low-carbon utilization and conversion of coal. Coal utilization mainly refers to the energy consumption domains of power generation, heating, industrial production, civil use, and chemical industry. Coal conversion refers to both the 


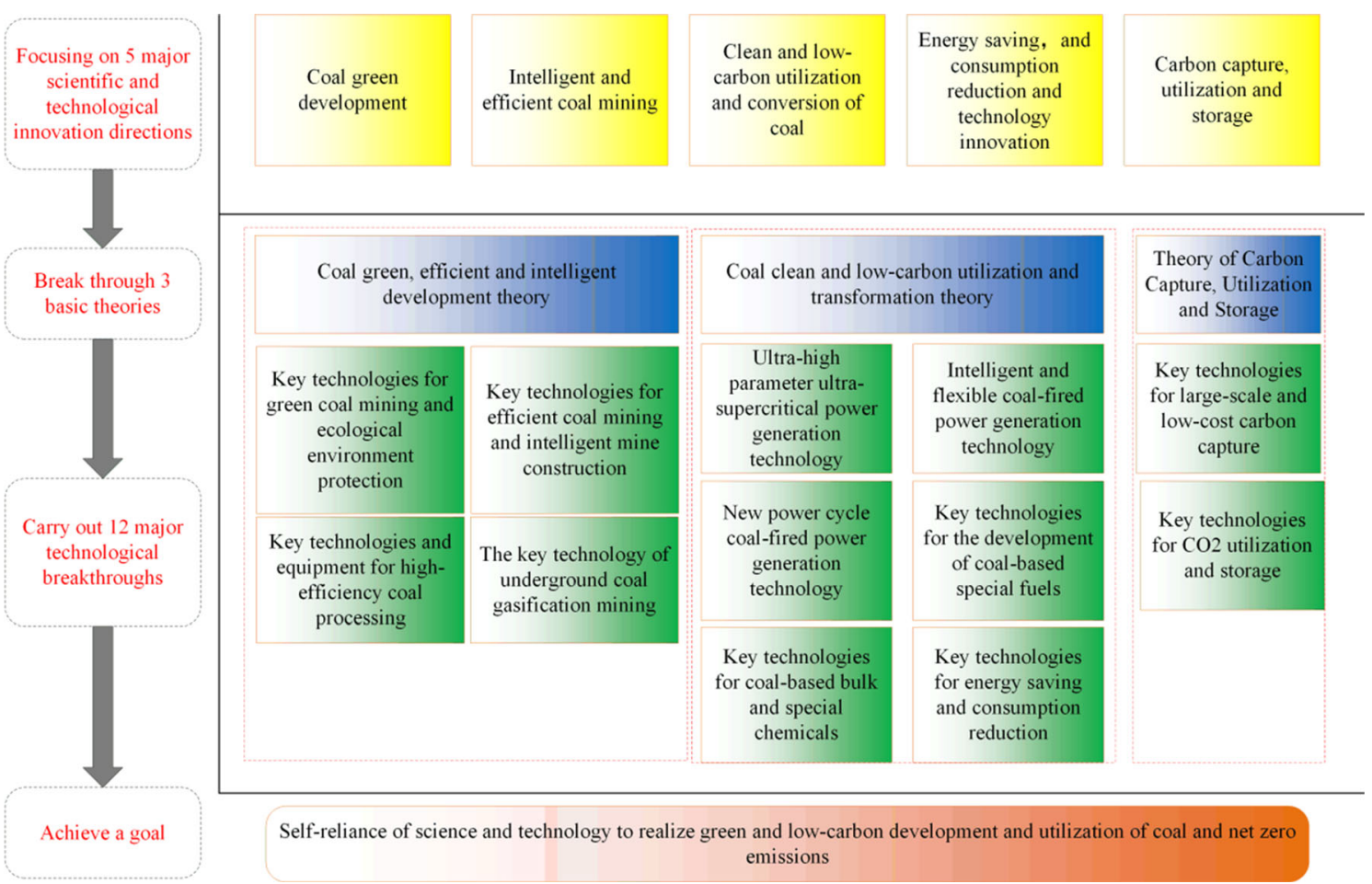

Fig. 7 Technical route for green and low-carbon development and utilization of coal

traditional coal chemical industry, such as coke, semi-coke, calcium carbide, coal-to-synthetic ammonia, and coal-tomethanol production, as well as modern coal chemical industry involving coal-to-liquid, coal-to-natural gas, and coal-to-olefin production as typical representative process.

The clean utilization of coal should focus on the next generation of safe, efficient, clean, low-carbon, smart and flexible coal-fired power generation technologies by greatly improving the efficiency of coal utilization, effectively supporting a high online proportion of renewable energy, and reducing carbon emissions. Furthermore, coal conversion should focus on the modern coal chemical industry by studying enhanced conversion technologies, high-efficiency conversion technologies for coal-based special fuel and industrial chain improvements to support the green development of the coal chemical industry.

\section{(4) Energy conservation and consumption reduction}

Energy conservation and efficiency improvements are the priority means of reducing carbon emissions. With respect to coal mining and washing technologies, research efforts should focus on the development and application of advanced technologies such as coal and rock identification technology, frequency conversion energy-saving technology, and unmanned mining technology. Advanced management, advanced equipment, high-quality personnel, etc. should be used to further reduce the energy consumption ratio of coal mining and achieve precision and digitization.
Energy-saving technology innovation should be pursued to realize the goals of energy conservation and consumption reduction. Energy-saving technologies and equipment for the power, metallurgical, chemical, and other industries should be developed to improve industrial energy conservation. Research on high-efficiency industrial boilers (kilns), new energy-saving motors, deep recycling of industrial waste energy, and industrial system energy-saving technologies based on advanced information technology are also expected to prove valuable.

(5) Carbon capture, utilization and storage Research by the International Energy Agency indicates that to achieve the $2{ }^{\circ} \mathrm{C}$ climate goal of the Paris Agreement, $14 \%$ of the cumulative emission reduction will originate from CCUS $\left(\mathrm{CO}_{2}\right.$ capture, utilization and storage) by 2060 , while $37 \%$ of any additional emission reduction will also come from CCUS. Many other international institutions such as the IPCC have also confirmed that without CCUS, international climate change goals cannot be achieved (United Nations 2020). The "Special Report on Global Warming of $1.5{ }^{\circ} \mathrm{C}$ " issued by the IPCC in 2018 pointed out that irrespective of whether the $1.5^{\circ} \mathrm{C}$ path model of a limited hedging project is used, it is necessary to apply carbon removal technology to remove 100 billion to 1000 billion tons of carbon dioxide during this century (Yuan 2017). 
In the field of CCUS, the focus is on the coverage and application of large-scale and low-cost CCUS technology in coal development, coal chemical industry, thermal power generation and other systems. As such, efforts should be made to evaluate the reliability, potential and economics of carbon sinks and carbon capture and storage technologies, while conducting research on intelligent monitoring technologies for the entire life cycle of carbon storage, etc.

\subsection{Key tasks of scientific and technological innovation}

\subsubsection{Basic theoretical research}

(1) Green, efficient and intelligent coal development theory

Green mining aims to reduce the impact of coal mining on the environment from the mining source by controlling or using the breaking motion of the mining rock strata, so as to realize the co-mining or protection of coal seams and associated resources (Qian et al. 2018). One particular focus should be the three evolution mechanisms of the stress field, fissure field and seepage field before, during and after mining, to develop a theory for water resource protection in coal mining. The mechanisms through which coal mining damages the land and the ecological environment should also be examined to reveal the transmission mechanism of mining damage; the evolution of surface ecology before, during and after mining should be investigated to reveal the self-repairing mechanism of surface ecology. The formation mechanism of methane gas flow in broken coal and rock mass under mining conditions should be studied, alongside the pressure relief and permeability enhancement mechanisms of single low-permeability coal seams and new principles of high-efficiency drainage, a standardized system for zero-methane-emission coal mine projects and the development of a circular economy in mining areas. High-precision geological prospecting methods and the basic theory of coal and rock identification should be developed, what should be done are to build a transparent mine, and provide basic geological guarantee for the intellectualization of coal mines (Peng 2020). Multi-source heterogeneous data fusion and information dynamic correlation theory should be explored in the context of mining, along with collaborative control theory for mining equipment under complex conditions. Dynamic collaborative control and data-driven decisionmaking theory oriented to complex mining environments could improve the intelligene and efficieny of coal mining (Liu et al. 2021).
(2) Clean and low-carbon coal utilization and conversion theory

With respect to the theory of clean coal utilization, the key aspects are the high-temperature material properties of large-capacity, high-parameter advanced ultra-supercritical generator sets, the combustion processes in the furnace and hydrodynamic characteristics in the pot, and basic theory pertaining to the heat transfer characteristics. The flow pattern optimization and reconstruction theory of supercritical circulating fluidized bed boilers should be investigated alongside the theory of clean and efficient coal combustion. The coupling of coal-based and renewableenergy-based power generation in multi-source input energy systems should be studied using integration optimization theory. The basic theory of the power cycles of new coal-based power generation systems, such as supercritical carbon dioxide and high-temperature solid oxide fuel cells for integrated coal gasification, should also be developed..

With repect to the theory of clean coal conversion, the key aspects are the reaction mechanisms and kinetics of coal conversion processes such as direct coal liquefaction, indirect liquefaction, and coal-to-olefins, and coal-to-alcohol processes. The physical and chemical properties of special coal-based oils such as high-gravity jet fuel, lowfreezing point diesel, and high-flash point jet fuel should be characterized. The kinetic mechanisms of low-rank coal conversion reactions, the influence of various heating modes on pyrolysis, the transformation behavior of the semi-coke structure and gasification reaction activity under different pyrolysis conditions, and the reaction kinetics under different gasification conditions should also be examined.

\section{(3) Carbon capture, utilization and storage theory}

Key points in CCUS include studying the basic theory of the chemical absorption reactions of carbon dioxide, and elucidating their mechanisms and pathway. The relationship between the molecular configuration of $\mathrm{CO}_{2}$ absorbents and the absorption performance should also be explored, alongside the basic theory of collection equipment design and system integration, the influence of material input, reactor structure, and packing structure on the mass transfer and reaction in the absorption process, and the potential heat recovery sites in the absorption reaction process. The potential and applicability of geological storage in saltwater aquifers and abandoned oil and gas wells should also be evaluated, alongside further development of the theories of carbon dioxide flooding, mineralization, flooding, and artificial photosynthesis. 


\subsubsection{Research and development of key technologies}

(1) Green coal mining and ecological environment protection

Under high-intensity large-scale mining conditions, strategies should be researched and developed for water resource protection; efficient treatment and utilization of mine water; remote sensing environmental monitoring of mining areas; mining damage monitoring and surface selfrepair; source detriment of intensive mining (Zhu et al. 2020); ecosystem reconstruction and land reclamation; intelligent monitoring and integrated transportation for underground coal mine reservoirs; integrated technology and equipment for underground mining, selection, and filling; and coal and gas co-mining.

(2) Efficient coal mining and intelligent mine construction

By exploiting the advantages of the internet, cloud computing, big data, virtual reality, etc. (Ge 2015 et al.), strategies should be researched and developed for transparent mining geological full information visualization technology, intelligent coal mining face complete sets of technologies and equipment, high-efficiency and rapid tunneling technology and equipment, large-scale hoisting equipment for 10 million-ton mines, intelligent power supply and distribution and energy-saving technologies for coal mines, massive data storage management and parallel analysis technology for mining, intelligent forecasting and decision-making systems for mining based on cloud services and big data, and mining perception, control, diagnosis and maintenance technologies.

(3) High-efficiency coal processing

Technologies should be researched and developed for fine heavy-medium separation of coal, high-efficiency dry coal preparation, coal product quality monitoring and intelligent control of the coal preparation process, modular washing with a capacity of 10 million tons per year, and the comprehensive utilization of coal slime in mining areas.

\section{(4) Underground coal gasification mining}

Underground gasifier site selection, directional drilling, and coal seam combustion stability control technology and equipment should be studied, alongside key technologies for the control of groundwater pollutants in underground coal gasification and mining.

(5) Ultra-high parameter and ultra-supercritical power generation

The overall design scheme of ultra-high parameter and ultra-supercritical Generator sets should be investigated. Processing and manufacturing technologies should be improved for key components, such as high- and medium- pressure steam turbine rotors, cylinders, valve casings, high-temperature blades, fasteners, and spool wear parts. Design and manufacturing technologies should be optimized for large-diameter high-temperature pipelines and fittings. Engineering demonstrations should be conducted for large-capacity and high-parameter ultra-supercritical secondary reheat units, ultra-supercritical circulating fluidized bed (CFB) boilers, and ultra-supercritical secondary reheating $\mathrm{CFB}$ boilers.

(6) Intelligent and flexible coal-fired power generation

Research should be conducted into boiler low-loadstable combustion technology for boilers, wide-load $\mathrm{NO}_{x}$ control guarantee technology, the optimal design of cold end systems suitable for deep peak shaving and high-efficiency operation of thermal systems under all working conditions, low-cost, high-efficiency, and flexible thermoelectric coupling technology, rapid load change and start/ stop technology, and the safety of unit flexible operation. In addition, the use of coal and municipal solid waste, sludge, renewable energy, and other non-coal fuel coupled power generation technologies should be evaluated. Key technologies for the system integration of arious coupling modes of coal and solar energy should be explored, and miniaturized high-parameter supercritical boilers of 50 $100 \mathrm{MW}$ should be developed to meet the requirements of regional energy and heating, in which biomass or municipal waste sludge may be used at the same time.

(7) New power cycle coal-fired power generation

Research should be conducted into new theories, new cycles, and new systems for coal-fired power generation under clean, low-carbon, high-efficiency, smart, and other multi-objective criteria. The design of $600{ }^{\circ} \mathrm{C}$ supercritical carbon dioxide power generation systems should be refined based on efficiency optimization and flexible peak shaving under all working conditions, and the industrial validation of generator sets should be completed. The optimal configuration and design methods for high-temperature solid oxide fuel cell power generation systems for coal gasification should be studied, alongside the development of system operation rules and key technologies to finalize the design and industrial validation of power generation systems.

\section{(8) Coal-based special fuels}

Research should be conducted into the next generation of direct coal liquefaction technologies under mild reaction conditions, high-temperature Fischer-Tropsch synthesis and other new indirect coal liquefaction technologies. Production technologies should be developed for the production of ultra-clean gasoline and diesel, military diesel, large-weight aviation kerosene, rocket diesel, and other special oils. Furthermore, technologies for coal-derived oil 
pretreatment, aromatic compound extraction, separation, and deep processing should be explored. Key technologies for the optimization and integration of direct coal liquefaction and indirect liquefaction, as well as high-temperature and low-temperature Fischer-Tropsch synthesis, should be developed. Finally, the localization of key equipment such as large-scale coal-to-liquid reactors and special pumps and valves should be examined.

(9) Coal-based bulk and specialty chemicals

New synthetic technologies and catalysts for coal-tomethanol, coal-to-olefin, and coal-to-ethylene glycol processes should be researched and developed. Technologies for the conversion of methanol to aromatics, naphtha and methanol to olefins, dimethyl ether carbonylation/hydrogenation of methyl acetate to ethanol, synthesis gas to high-carbon primary alcohols, and coal to polymethoxy dimethyl ether, as well as alkylation of methanol to toluene to p-xylene, and the production of calcium carbide by the coal-oxygen thermal method should also be investigated.

(10) Energy conservation and consumption reduction New energy-saving technologies should be developed for industrial boilers based on high-efficiency pulverized coal boilers, large-scale fluidized bed boilers, gas-fired boilers with full heat recovery from the flue gas, blast furnace gas boilers for stable combustion with heat storage, high-efficiency and low-nitrogen decoupling combustion (stratified combustion), new low-temperature economizers, and intelligent soot blowing optimization and online coking warning systems. Research should also be conducted into new energy-saving technologies for high-efficiency motors and equipment, such as new self-excited asynchronous three-phase motors, reluctance motors, and rare earth permanent magnet synchronous motors. In addition, technologies for waste heat recovery from metallurgical slag, waste heat and pressure energy recovery from metallurgical processes, and coaxial unit application industrial waste energy recovery should be researched and developed. Finally, visual energy management optimization systems for energy-intensive industries, such as steel, building materials, and petrochemicals, should be developed.

(11) Large-scale and low-cost carbon capture

New and efficient materials for $\mathrm{CO}_{2}$ absorption, as well as gas and liquid secondary pollutant control technology, should be developed. Research should be conducted into new capture technology and equipment amplification technology, improved absorption and regeneration processes, enhanced coupling and integration of capture and power generation systems, and the development of proprietary core equipment. The synergistic removal of $\mathrm{CO}_{2}$, fine particles, $\mathrm{SO}_{2}$ and other pollutants should be explored.

\section{(12) $\mathrm{CO}_{2}$ utilization and storage}

The utilization of $\mathrm{CO}_{2}$ flooding/gas flooding and storage technologies for special oil and gas reservoirs should be investigated, alongside. $\mathrm{CO}_{2}$ mineral conversion, fixation, and utilization technologies for carbon dioxide based on the large amounts of solid waste generated by industrial production. $\mathrm{CO}_{2}$ mineralization power generation technologies for large-scale industrial alkaline solid waste and natural alkaline minerals should also be examined. Safe and reliable carbon dioxide storage and monitoring technologies should also be explored with considertion of the geological storage mechanism, long-term migration behaviour, and prediction methods.

\section{Guarantee measures for green and low-carbon development and utilization of coal}

(1) Establish a carbon emission management system and an evaluation and supervision system for the green and low-carbon development and utilization of coal

It is imperative to improve the varying carbon emission reduction assessment and management systems of mining companies and establish a unified carbon emission management system as soon as possible. As such, the current status of the cabon emissions of mining companies should be determined, the preparation of a carbon emission reduction plan should be initiated, and appropriate strategies for low-carbon development should be formulated. An evaluation system for the green and low-carbon development and utilization of coal should also be established to accelerate the improvement of the industry, vigorously eliminate outdated production capacity, prohibit the use of obsolescent technology and equipment, and implement a special supervision system. An accountability system for the green and low-carbon development and utilization of coal should also be developed, especially for companies that do not perform well.

(2) Accelerate the technological innovation of the green and low-carbon development and utilization of coal, and start the major project of "2030-Clean and High-Efficiency Utilization of Coal" as soon as possible

Taking the major project "2030-Coal Clean and Efficient Utilization" as the impetus, a technology innovation system should be established for the green and low-carbon development and utilization of coal with enterprises as the main body, and the establishment of R\&D platforms such 
as national key laboratories and national engineering centers to accelerate scientific and technological investment and innovation. A number of major project demonstrations should be arranged for the promotion and wider application of the scientific and technological achievements to continuously improve the scientific and technological innovation capabilities of coal development and utilization.

(3) Strengthen carbon emission reduction awareness, publicity, and education

A training system should be established for energy conservation and carbon emission reduction in coal development and utilization enterprises, in which all employees receive education and training for all employees in groups to improve their ideological awareness. Implementation plans should also be organized and compiled for green coal development and utilization in high-energy-consuming industries. Advanced enterprises should be selected to establish training bases and carry out technical experience exchanges.

\section{Conclusions}

(1) Through a systematic analysis of China's energy production and consumption structure, carbon emission status, coal resource consumption status and development trend, it is found that China's carbon emission reduction pressure is huge, and the carbon emissions generated by coal consumption account for $75.7 \%$ of the total carbon emissions from fuel energy combustion. Coal consumption by the industrial sector accounts for $87 \%$ of the total, of which high energy-consuming industries such as electricity production, metal smelting and processing, and chemical raw material and chemical product manafcture, are the main coal users. Under the goal of carbon neutrality, the realization of the safe, efficient, green and low-carbon development and utilization of coal through technological and management innovation is expected to be of great significance to guaranteeing hina's energy security and high-quality economic development.

(2) The current status of China's green coal development and low-carbon utilization and conversion technologies have been systematically studied and summarized. Three basic theories, namely, green, efficient, and intelligent coal development theory, clean and low-carbon utilization and conversion theory, and carbon capture, utilization and storage theory have been put forward along with 12 key technologies, with the ultimate goal of achieving net-zero emissions from the green and low-carbon development and utilization of coal.

(3) A carbon emission management system for evaluating the green and low-carbon development and utilization of coal, accelerated innovation in coal science and technology, and the strengthening of carbon emission reduction awareness through increased publicity and education, etc., have been proposed with institutional mechanisms and safeguards to promote scientific and technological innovation in green and low-carbon development and utilization of coal.

Open Access This article is licensed under a Creative Commons Attribution 4.0 International License, which permits use, sharing, adaptation, distribution and reproduction in any medium or format, as long as you give appropriate credit to the original author(s) and the source, provide a link to the Creative Commons licence, and indicate if changes were made. The images or other third party material in this article are included in the article's Creative Commons licence, unless indicated otherwise in a credit line to the material. If material is not included in the article's Creative Commons licence and your intended use is not permitted by statutory regulation or exceeds the permitted use, you will need to obtain permission directly from the copyright holder. To view a copy of this licence, visit http://creativecommons. org/licenses/by/4.0/.

\section{References}

BP Amoco (2020) Statistical review of world energy. BP Amoco Press

BP (2019) BP energy outlook 2020. https://www.bp.com/en/global/ corporate/news-and-insights/pressreleases/bp-energy-outlook2020.html

China Energy Statistical Yearbook 2019 (2020) China Statistics Press, Beijing

Ge S, Su Z, Li A, Wang S, Hao S, Liu W, Meng L (2015) Study on the positioning and orientation of a shearer based on geographic information system. J China Coal Soc 40(11):2503-2508

Intergovernmental Panel on Climate Change (IPCC) (2018a) Special report on global warming of 1.5 . https://www.ipcc.ch/sr15/

Intergovernmental Panel on Climate Change (IPCC) (2018b) The Synthesis Report of the Fifth Assessment Report of the IPCC. Intergovernmental Panel on Climate Change

Li Q, Zhang K (2021a) The path for green development and utilization of energy in China. Strat Study CAE 23(1):101-111

Li Q, Guo J, Zhang K, Yan Y, Zhang C, Xu Z (2021b) Damage conduction mechanism and key technology of source loss reduction of intensive coal mining in the West. J China Coal Soc. https://doi.org/10.13228/j.cnki.jccs.2020.1695

Liu F, Cao W, Zhang J, Cao G, Guo L (2021) Current technological innovation and development direction of the 14th five-year plan period in china coal industry. J China Coal Soc 46:1-16. https:// doi.org/10.13225/j.cnki.jccs.2021.0042

Peng S (2020) Current status and prospects of research on geological assurance system for coal mine safe and high efficient mining. J China Coal Soc 45(7):2331-2345

Qian M, Xu J, Wang J (2018) Further on the sustainable mining of coal. J China Coal Soc 43(1):1-13 
The Ministry of Ecology and Environment (2020) The Ministry of Ecology and Environment Held a Briefing on Policies to Actively Respond to Climate Change. http://www.mee.gov.cn/ ywdt/hjywnews/202009/t20200927_800752.shtml

United Nations (2020) United Nations Climate Change Annual Report 2019

Yu B, Zhao G, An R, Chen J, Tan J, Li X (2021) Study on China's Carbon emission path under the carbon neutral target. J Beijing Inst Techno (soc Sci Edi). https://doi.org/10.15918/j.jbitss10093370.2021 .7380
Yuan L (2017) Strategies of high efficiency recovery saving for coal resources in China. Science Press, Beijing

Zhang J, Zhang L (2021) Preliminary discussion on development of carbon capture, utilization and storage for carbon neutralization. Therm Power Gen 50(1):1-6

Zhu T, Wang R, Yi N, Niu W, Wang L, Xue Z (2020) $\mathrm{CO}_{2}$ and $\mathrm{SO}_{2}$ emission characteristics of the whole process industry chain of coal processing and utilization in China. Int J Coal Sci Technol 7(1):19-25 